\title{
Design of Wireless Power Transfer for Heart Assist Devices
}

\author{
K.R.Sughashini, B.K.Chitra,T.Surendran, K.Nandini, M.Suganya
}

\begin{abstract}
Heart assist devices are designed for helping damaged hearts maintain sufficient blood flow, for patients getting heart attack with short term and it is used for congestive heart failure patients. The frequency with which the patients are being operated to replace the battery of these devices can be aided and reduced by wirelessly transmitting power. The transcutaneous power transfer for the devices requires charges that move outside the body to induce charges to move inside the body which can ultimately be used to supply energy to the heart pump. WPT is a method of transmitting wireless power using an external primary coil to generate a magnetic field. It passes through the skin and induces current in an implanted secondary coil. The infection caused due to surgery is removed by WPT method. To monitor the charging level of the battery the Wi-fi module is used. It also monitors the corresponding blood flow and the pulse during this function.
\end{abstract}

Keywords :Alternating current, transcutaneous energy transfer.

\section{INTRODUCTION}

Electricity is one of the most important one in the day today life . From the beginning of mankind, there always has been the necessity of power, which brought us to the inventions of fire, steam engines and most importantly, electricity. Now a days alternating current is generated from power grid for residential and commercial purpose.

The generated power delivers to load centers through high voltage transmission lines and send to step down transformers with losses. During the distribution end the voltage is RI 2 step down for efficient distribution of transmitted power and the consumers consume at its desired low voltage level. This AC current is necessary for our everyday life, for example, lights, fans, home appliances, sockets, and so on. The components are standardized with the help of electrical wire.

Device used for rated standard current and voltage will work over millions of outlets throughout the country. But standards differ between countries to countries, the perfectly rated device will work in the limited electrical system .But in this case, the complexity is wire or cord. Problems like short circuited, burning wires, plug in/out, twisting etc. Apart from the conventional transmission system, wireless power transmission is more efficient, modern and really needed technology to be developed.

Revised Manuscript Received on 14 September, 2019.

K.R.Sughashini, EIE, Easwari engineering college, chennai, Tamil Nadu, India. (Email: sughashinikrme@gmail.com).

B.K.Chitra, EIE, Easwari engineering college, chennai, Tamil Nadu, India. (Email: chitra.balakrishnan93@gmail.com)

T.Surendran, EIE, Easwari engineering college, chennai, Tamil Nadu, India.

K.Nandini, EIE, Easwari engineering college, chennai, Tamil Nadu, India.

M.Suganya EIE, Easwari engineering college, chennai, Tamil Nadu, India.

\section{IMPLANTABLE DEVICES}

Implantable medical devices have the potential to change a clinical condition almost instantly. One example is the use of a left ventricular assist device to restore blood flow when the natural heart is unable to maintain the flow rates required. Other examples of smart devices include pacemakers, nerve stimulators and drug pumps. These devices require electrical energy to operate, the provision of energy is a critical aspect of their design. This project addresses the issue of providing substantial power sufficient for a heart pump operating continuously for the remaining lifetime of a patient. The basis of what this design proposes is the use of inductive coupling and a magnetic field to move power from outside the body to inside [18]. The key challenges are related to alignment of components and avoidance of any heating problems. New power electronic techniques have been developed to address these issues .

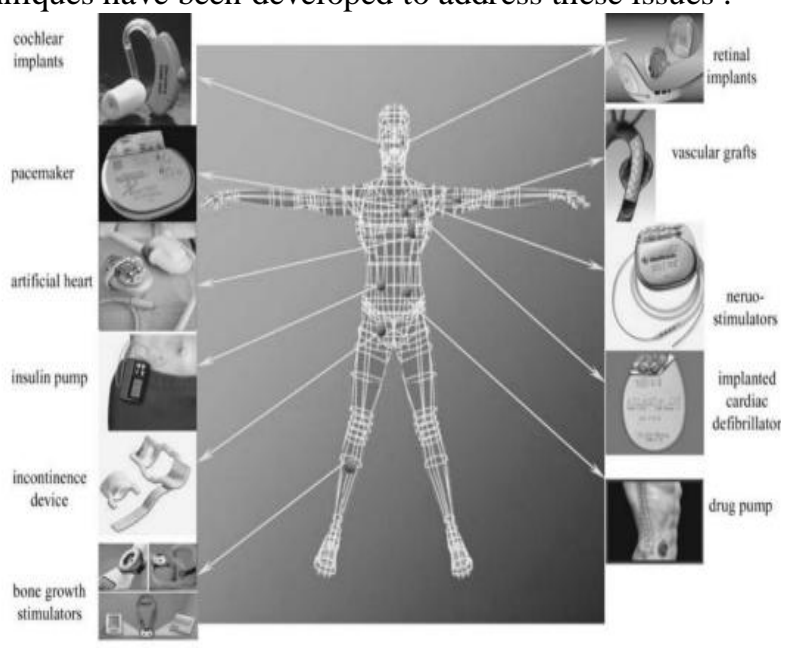

Fig.1 Implantable devices in body

\section{RISKS IN PERCUTANEOUS CABLE}

Heart assist devices are designed for helping damaged hearts maintain sufficient blood flow, with short term and it is use to required for patients recovering from heart attack and for patients who are suffering congestive heart failure it is used as long term. By 1998 continuous flow rotary blood pumps were introduced and soon these are followed by hydro dynamically and magnetically levitated rotary pumps. The future aim is a transcutaneous energy transfer (TET) based rotary pump total artificial heart device.

Published By: 


\section{Design Of Wireless Power Transfer For Heart Assist Devices}

Heart Pumps motors to create blood flow, and this power is delivered through a percutaneous driveline from external batteries. The percutaneous drive line provides a reliable, highly efficient method of getting the power from outside the body to the heart pump motor controller, but its major drawback is its requirement for penetration through the skin and the associated risks of infection.

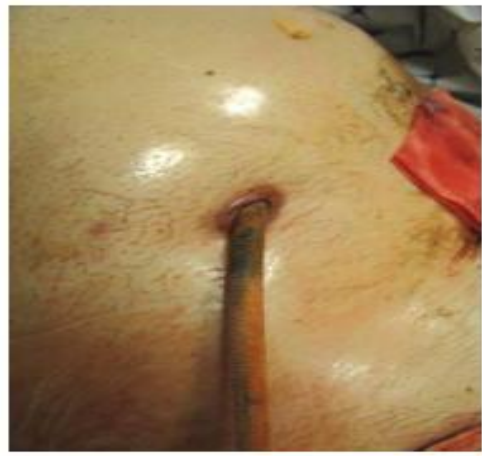

Fig2. Driveline exit site

The driveline breaks the skin and the torque generated by everyday patient movements and the weight of the battery can damage this chronic wound, leading to relapsing infections and patient mortality. The initial driveline infection can spread elsewhere and cause bloodstream infection. Over time, driveline infections are very difficult to control despite on-going efforts to treat them . Eliminating this percutaneous driveline could significantly reduce the number of adverse infection effects.

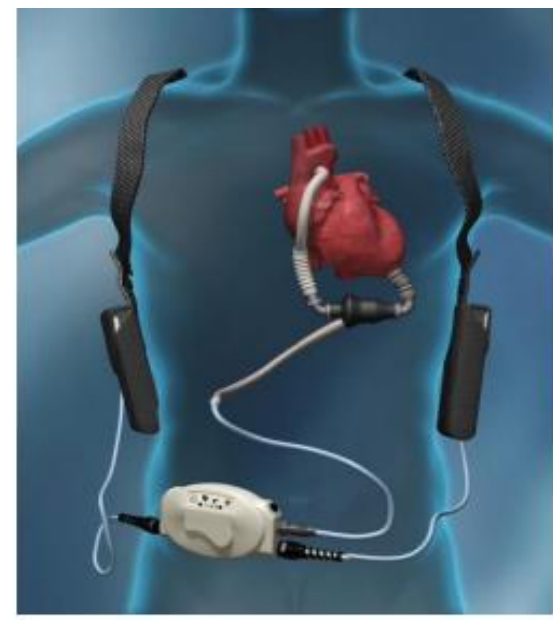

Fig.3wired pacemaker

\section{GENERAL PRINCIPLE OF DESIGN}

The general principle of Wireless power Transmitter is the usage of inductive coupling and the transfer of power at maximum efficiency with the power transfer nearer to the field. This model also ensures the versatility and optimization of the battery charging circuit, which is a energy efficient and prevented losses. The circuit is mainly classified into two divisions:

1. circuit of transmitter

2. Circuit of receiver

The transmitter circuit consists of a power supply, boost converter, copper coils and royer oscillator while the receiver circuit has the receiver coil, rectifier, Pulse sensor ,Flow sensor, At mega 328 microcontroller and a switching circuit that uses CD4066

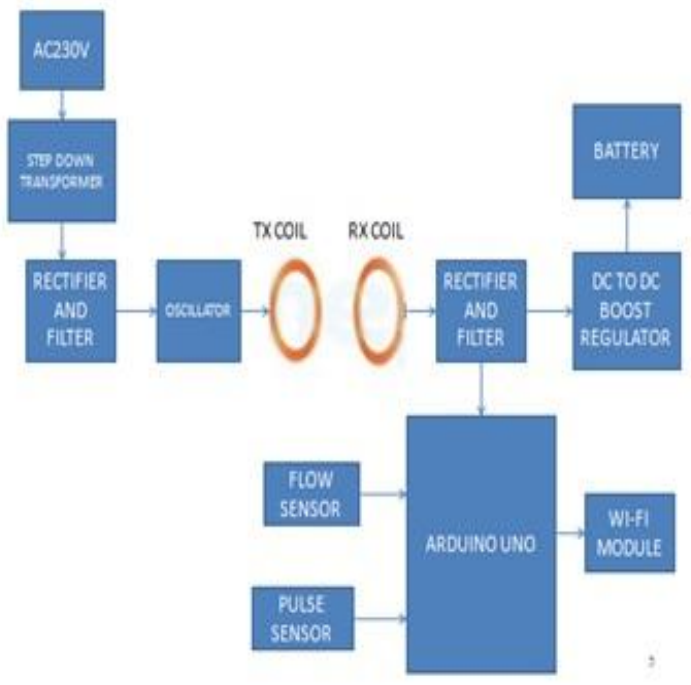

Fig.4 Block diagram for wireless Pacemaker

An AC power is fed to the power supply which is acquired from the mains. It is stepped down and then rectified to give dc power. In order to obtain a constant $12 \mathrm{v}$ a dc voltage is passed through a voltage regulator (LM7805) . The $12 \mathrm{~V}$ now becomes the input to the royer oscillator . This oscillator then alters the received DC voltage to AC power with a high frequency.

When we placed the receiver coil near the field range from the transmitter coil, the magnetic field produced in the transmitter coil extends and it induces an AC voltage which generates a current flow in the receiver coil of the wireless charger. The transmitted AC voltage is then fed to the rectifier which converts it to DC. To eliminate the ripples capacitor filter is used. To ensure that the voltage regulated is constant the rectified voltage is fed to the voltage regulator LM7805. The output is regulated $5 \mathrm{~V}$ dc.

This power then goes to microcontroller. To develop the wireless power transfer the following devices are required

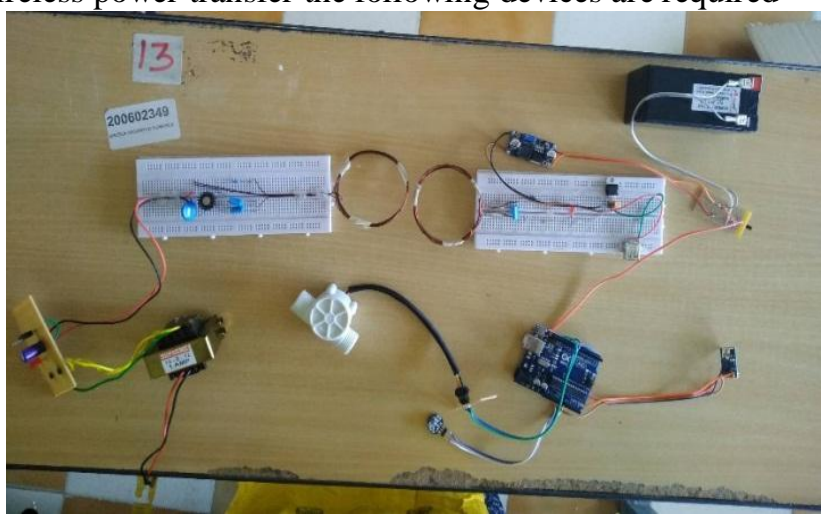

Fig.5 Experimental setup

1. Circuit Design and assembly of the power supply unit.

To step down a $230 \mathrm{~V}$ ac supply from the mains to a $12 \mathrm{~V}$ ac high frequency the power supply is used. This $12 \mathrm{~V}$ ac is then rectified to give $5 \mathrm{~V}$ dc.

\section{Rectify and regulate voltage.}

$12 \mathrm{~V}$ ac is rectified to dc supply and are filtered to remove any noise signals.

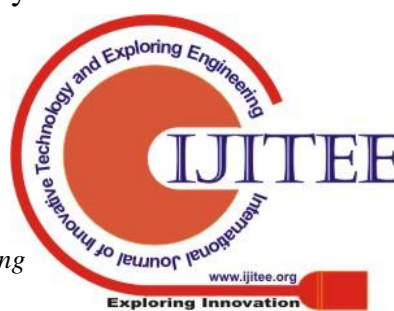




\section{Oscillator designing:}

royer oscillator is one of the most important components.

These are the components are needed for transmitter module. The assembled and fabricated model is shown in the figure below.

\section{To Develop a transmitter and receiver coils.}

Electromagnetic induction occurs between these two coils and an emf produced on the TX coil which induces a current on the RX coil. The coils were embedded on the fabricated casing of the modules. However they are as in the figure below

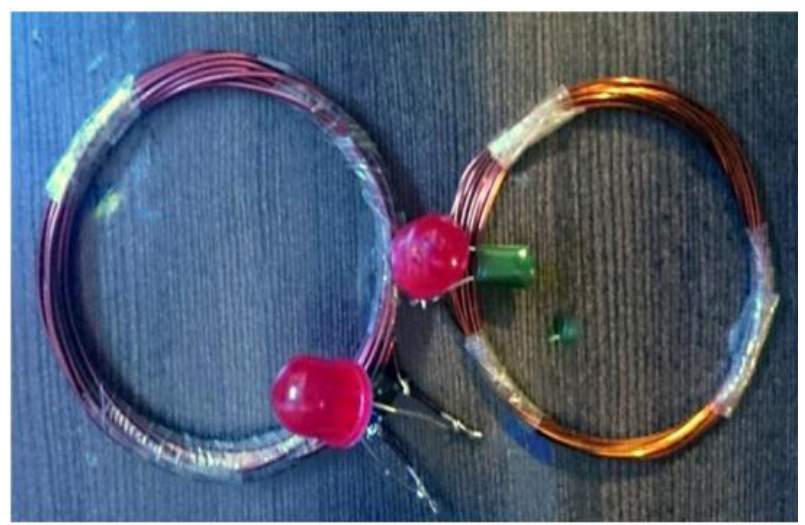

Fig.6 Transmitter \& Receiver coil

\section{Design the receiver module.}

A rectifier is needed to obtain dc output power which would be used to deliver power to other devices.

\section{Designing a socket charging circuit.}

The transmitted power is used for battery charging for further demonstration of wireless power transmission in the

\section{Design a pulse and a flow sensor unit.}

Pulse sensor and the flow sensor are connected to the microcontroller with their own software coding in order to check the vitals during the charging.

\section{LIMITATIONS}

The major problem of wireless power transfer using transmission coil is, the efficiency is inversely proportional to the distance. As a result, it can transfer very low power at higher distances. So, the overall efficiency is low.

Another major problem of wireless power transfer is, all devices, which are in the range of the coil, will act as a receiver and draw a load. Every device, which will be charged wirelessly, should have built in over current protection as the current in the air will be high enough to transfer power efficiently. The wireless system is easy and safe, comparing to the previous systems. But, it is costly. Our body can resist to low frequency voltages and hence this prototype does not cause any hazard to the health.

\section{FUTURE SCOPE}

To improve the future scope by wpt there are many ways, reducing the size by multilayer coil gives easy integration, by means of antenna coil transmission range can be increased. For maximum power transfer, $50 \Omega$ impedance is needed. For an impedance matching circuit 1 and c elements modern world.

are inserted between the band and the output of the final stage amplifier. Insert more rf power amplifiers and current for improving the transmission range.

\section{RESULT AND DISCUSSION}

The oscillating circuit was the main part of this experience. We have to increase the frequency more than 50 $\mathrm{kHz}$ to make the coil work. The efficiency of wireless power transfer mostly depends on the capacitor values of the oscillating circuit. The simulation part shows that, if we change the capacitor value, the frequency changes and with higher frequency, we can transfer more power wirelessly to higher distances. This indicates that the efficiency and the range can be improved.

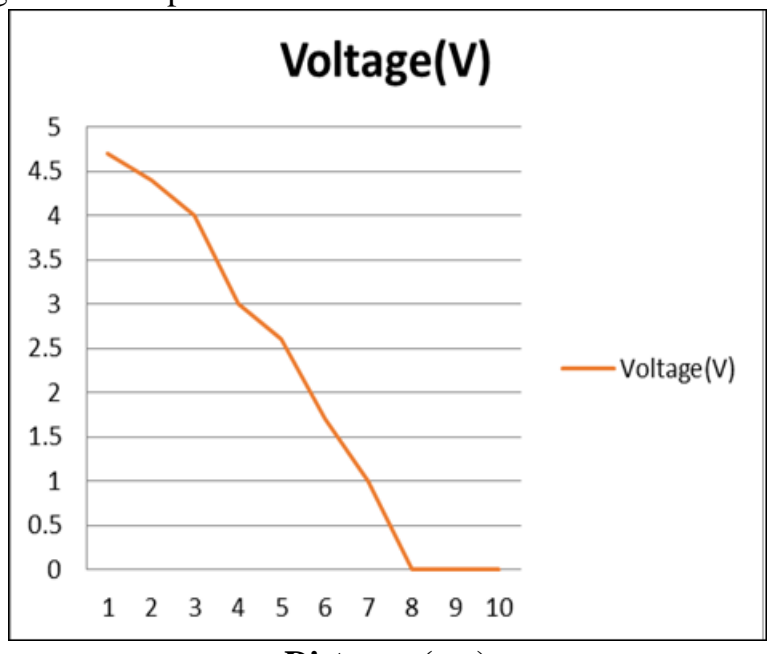

Distance (cm)

Fig.7 Represents the graphical representation of Distance Vs Voltage

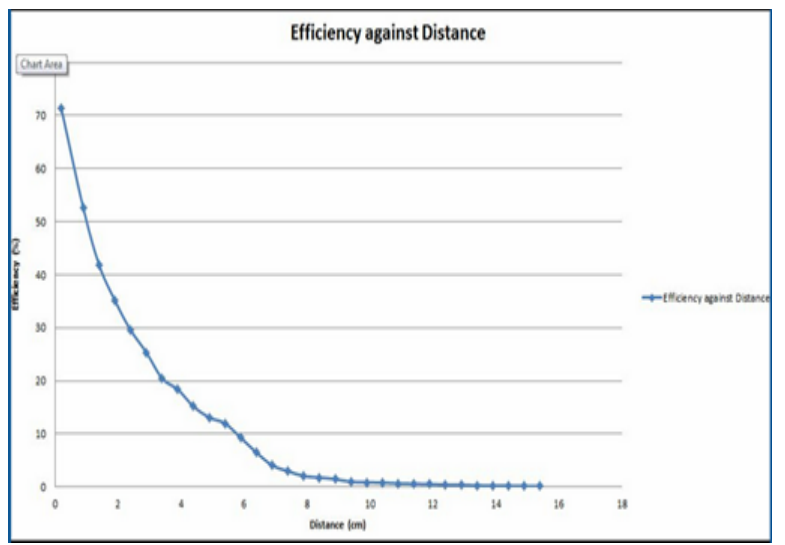

Fig.8 Represents the efficiency of the voltage applied

\section{CONCLUSION}

The proposed paper delivers power wirelessly and showed positive results. We were able to transfer power wirelessly and the efficiency was $1.4 \%$ which is very low. But, from the research, we found that, the efficiency can be increased. As the output power is inversely proportional with the distance, it is very much challenging to improve the efficiency.

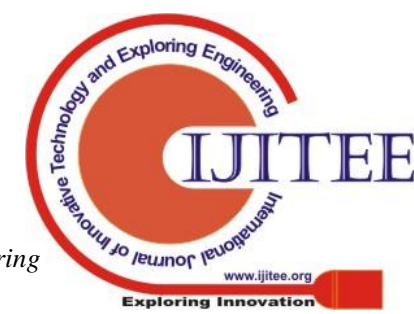


This project shows many promises to the medical systems. But, to do so, we have to increase the efficiency first. If we can develop this design to get a high enough efficiency, we might be going for the large scale wireless power transmission for other implants.

\section{REFERENCES}

1. D. Chattopadhyay (2006), Electronics fundamentals And Applications 7th Ed. New Dehli, India: New Age Pub.

2. Paul Horowitz and Winfield Hill (1989), The Art of Electronics, 2nd Ed. Cambridge, England: Cambridge Univ. Press.

3. U.A. Bakshi and A.P.Godse (2008), Electronic Devices And Circuits I, 3rd Ed. Pune, India: Technical Pub.

4. Dr. Morris Kesler (2013) Highly Resonant Wireless Power Transfer: Safe, Efficient, and over Distance.

5. Mizuno, T., Yachi, S., Kamiya, A. , Yamamoto, D (2011), Improvement in Efficiency of Wireless Power Transfer of Magnetic Resonant Coupling Using Magnetoplated Wire. IEEE Transactions on Magnetics.

6. Bu, Yinggang \& Wang, Wenhua \& Kasai, Takahiro \& Mizuno, Tsutomu (2016), 'Improvements in the Transmission Efficiency in an Electric Vehicles Wireless Power Transfer System Using Litz Magnetoplated Wire', pp. 1-4.

7. A. Karalis, J. D. Joanopoulos and M. Soljacic (2008), "Efficient wireless non-radiative mid-range energy transfer", Ann. Phys., vol. 323, no.1, pp.34-48.

8. Barton B. Anderson (2000), The Classic Tesla Coil, A Dual Tuned Resonant Circuit, Ann. Phys., vol. 323, no.1, pp.34-48.

9. Dept Electron Eng., Helsinki Metropolia University of Applied Sciences, Helsinki, Finland.

10. Q. Yuan, Q. Chen, and K. Sawaya (2010), "Maximum transfer efficiency of wireless power transfer system with resonant/non-resonant transmitting/receiving elements," Proc. 2010 IEEE Antennas and Propagation Society International Symposium, p. 521.6, Toronto, Canada.

11. Electronicshub.org. (2015). Open Circuit and Short Circuit Test on Transformer. Retrieved from https://www.electronicshub.org/open-circuit-and-shortcircuit-test-on-transformer.

\section{AUTHORS PROFILE}

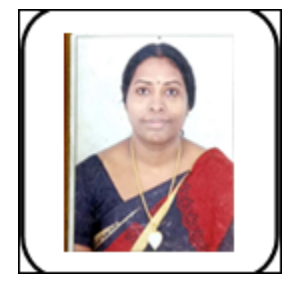

K.R.sughashini was awarded B.E in EEE from Anna university and M.E in Power Electronics from Anna University. She is making a significant original and innovative contribution to the advancement of scholarship and research. Her publications are "INTELLIGENT HOME HEATING SYSTEM", IJRET, vol 01,issue 02,Oct 2012,pp 104-107. ,"

FUZZY BASED CONTROL USING LabVIEW FOR MISO TEMPERATURE PROCESS", IJRET, vol 01,issue 02,Oct 2012,pp109114. 